CLINICAL STUDY

\title{
Adrenocortical carcinoma: clinical outcomes and prognosis of 330 patients at a tertiary care center
}

\author{
Montserrat Ayala-Ramirez*, Sina Jasim ${ }^{1, *}$, Lei Feng ${ }^{2}$, Shamim Ejaz, Ferhat Deniz, Naifa Busaidy, \\ Steven G Waguespack, Aung Naing ${ }^{3}$, Kanishka Sircar ${ }^{4}$, Christopher G Wood ${ }^{5}$, Lance Pagliaro ${ }^{6}$, \\ Camilo Jimenez, Rena Vassilopoulou-Sellin and Mouhammed Amir Habra \\ Department of Endocrine Neoplasia and Hormonal Disorders, Unit 1461, The University of Texas MD Anderson Cancer Center (UTMDACC), 1515 \\ Holcombe Boulevard, Houston, Texas 77030, USA, ${ }^{1}$ Department of Medicine, St Louis University, St Louis, Missouri, USA, Departments of ${ }^{2}$ Biostatistics, \\ ${ }^{3}$ Investigational Cancer Therapy, ${ }^{4}$ Pathology, ${ }^{5}$ Urology, ${ }^{6}$ Genitourinary Medical Oncology, UTMDACC, Houston, Texas, USA \\ (Correspondence should be addressed to M A Habra; Email: mahabra@mdanderson.org; R Vassilopoulou-Sellin; Email: rsellin@mdanderson.org)
}

*(M Ayala-Ramirez and S Jasim contributed equally to this work and should be acknowledged as first authors)

\begin{abstract}
Objective: Adrenocortical carcinoma (ACC) is a rare malignancy with a poor prognosis. Herein, we describe the clinical features and outcomes for a large series of ACC patients.

Design and methods: Retrospective review of ACC patients seen at The University of Texas MD Anderson Cancer Center from 1998 through 2011.

Results: A total of 330 patients with median age at diagnosis of 48.5 years; 12 (3.6\%) patients were under 18 years. Hormonally functioning tumors represented $41.8 \%(n=138)$ of all cases. Surgical resection for the primary tumor was done in 275 (83.3\%) patients (45 at MD Anderson (16.4\%)). For those who had surgical resection, the median local-recurrence-free time was 1.04 years. Factors associated with local recurrence included positive surgical margins $(P=0.007)$ and advanced disease stage $(P=0.026)$. Median overall survival time for all patients was 3.21 years. Median survival times were $24.1,6.08,3.47$, and 0.89 years for stages I, II, III, and IV respectively. In multivariable analysis, older age, functioning tumors, and higher disease stage remained significant prognostic factors associated with poor survival.

Conclusion: ACC prognosis remains poor with the use of currently available treatments. Older age, functioning tumors, and incomplete resections are clinical factors associated with poor survival. Surgical expertise is important to achieve complete resections and to improve outcome.
\end{abstract}

European Journal of Endocrinology 169 891-899

\section{Introduction}

Adrenocortical carcinoma (ACC) is a rare and aggressive malignancy with an estimated annual incidence of about two cases per million people $(1,2,3)$. Most of our knowledge about ACC is derived from case series that reflected national databases and tertiary referral centers' experience $(4,5,6,7,8)$.

As the first case series of malignant suprarenal tumors was described by Ramsay in 1899 (9), many milestones have been reached in the treatment and management of ACC, including the discovery of cortisone in the 1940s (10) and the introduction of mitotane in the 1960s (11). In the past few decades, better characterization of the molecular alterations that may occur in these tumors (TP53 mutation found in $\mathrm{Li}-$ Fraumeni syndrome (12), the APC and CTNNB1 genes in familial adenomatous polyposis coli $(13,14)$, and the CDKN1C (15) and IGF2 $(16,17)$ genes associated with Beckwith-Wiedemann syndrome) have led to the proposal of therapeutic interventions and prognostic markers in ACC $(18,19,20)$. Since the publication of the last MDACC case series (5), multiple important developments have occurred, including the introduction of two staging systems (by the International Union Against Cancer in 2004 (21) and by the European Network for the Study of Adrenal Tumors (ENSAT) in $2009(22,23))$ and the completion of the first phase III clinical trial in ACC (24).

Despite these promising developments, the estimated 5-year overall survival rate for ACC patients remains poor at $15-44 \%(7,25,26,27)$. In this study, we summarize important clinical features of a large cohort of ACC patients to assess outcomes and treatment utilization in ACC over the past decade, including factors affecting prognosis. We also compared those findings with earlier reports from the same institution $(4,5,25)$. Finally, we presented our current algorithms that we use to manage patients with ACC. 


\section{Subjects and methods}

\section{Patient records and study design}

With the approval of the institutional review board, we retrospectively reviewed the data for ACC patients from the Tumor Registry Database of the Department of Medical Informatics at The University of Texas MD Anderson Cancer Center from 1998 through 2011. We selected 1998 as our previous series was published in 2001 and included patients from 1980 to 1997 (5).

To ensure the accuracy of this retrospective analysis, data were extracted and entered into duplicate datasets by two independent groups of investigators (S J, S E, F D, and $\mathrm{M} \mathrm{A} \mathrm{H}$ ). Data fields for demographics, clinical outcomes, laboratory tests, imaging, pathologic diagnosis, and treatments were subsequently reviewed, verified, and reconciled into one database using Microsoft SQL Server version 2008 (Microsoft Corporation). It is our standard practice to confirm the diagnosis of ACC upon referral to MD Anderson for those patients who had outside surgery or biopsy before referral. The reporting of Weiss score and other markers of cell proliferation was not routinely performed and thus were not included in this report. Functional status of the tumor was determined through documentation in the medical records of cortisol, aldosterone, and/or androgen hypersecretion. Overall survival time was calculated from the date of tissue diagnosis to the date of death or to the last follow-up date. Time to local recurrence was calculated from the date of first surgical intervention. Patients who died without local recurrence were censored at the date of death. Patients were censored at the last follow-up if local recurrence or death had not occurred.

Resection margins were determined by reviewing pathology, operative reports, and perioperative records and defined as follows: R0, no evidence of tumor; R1, microscopically positive resection margins; $\mathrm{R} 2$, macroscopic residual disease; RX, status of resection margins is unknown.

We used the ENSAT staging classification because of its better prognostic accuracy when compared with the International Union Against Cancer staging classification for ACC $(22,23)$. The ENSAT staging system defines stage I as ACC measuring $\leq 5 \mathrm{~cm}$ in greatest dimension confined to the adrenal gland, stage II as tumor $>5 \mathrm{~cm}$ without extra-adrenal invasion, stage III by the presence of positive lymph nodes, infiltration of surrounding tissue, or vascular tumor extension, while stage IV includes only patients with distant metastases (22). This staging system has been in use in our institution since 1995 as proposed by Lee et al. (28) and was done at the time of operation for the 275 patients who underwent surgery and at the time of diagnosis for the 55 patients who did not have resection of the primary tumor.
We also compared patients' characteristics and outcomes from this cohort with those reported previously from the same institution. As we did not have the original datasets for patients reported before 1998, we defined disease burden as follows: local (stage I and stage II), regional (stage III), and distant (stage IV) to facilitate comparing the results of different series.

\section{Statistical analyses}

Frequencies and percentages were reported for categorical variables. Fisher's exact test or $\chi^{2}$ test was used to evaluate association between two categorical variables. The Wilcoxon rank-sum test was used to evaluate the difference in the distribution of continuous variables between patient groups. The Kaplan-Meier method was used to analyze time-to-event endpoints, including overall survival and time to local recurrence. The logrank test was used to evaluate differences in these endpoints between patient groups. Multivariable Cox proportional hazards models were fitted to include important demographic and clinical variables. All tests were two-sided. $P$ values $<0.05$ were considered statistically significant. Statistical software packages SAS 9.1.3 (SAS Institute, Cary, NC, USA) and S-Plus 8.0 (TIBCO Software, Inc., Palo Alto, CA, USA) were used for all analyses.

\section{Results}

\section{Patients' characteristics}

Three-hundred and thirty patients with ACC were included in the current study. Most were Caucasian $(n=281,85 \%)$ and female $(n=212,64.2 \%)$. The median age was 48.5 years (range, 0-86 years); 12 patients $(3.6 \%)$ were under the age of 18 years. ACC was associated with hormonal overproduction in 138 patients $(41.8 \%)$ as follows: cortisol overproduction in 76 patients $(55.1 \%)$, aldosterone overproduction in 14 patients $(10.1 \%)$, androgens overproduction in 21 patients (15.2\%), and overproduction of more than one hormone in 27 patients (19.6\%). Median tumor size was $11 \mathrm{~cm}$ (range, 1-27 cm) and median tumor weight was $308 \mathrm{~g}$ (range, 4-3500 g). There were no cases of bilateral ACC in our cohort. Table 1 summarizes the important clinical features of this cohort and Table 2 describes patients' characteristics and outcomes in this study compared with those reported previously from the same institution.

\section{Associated malignancies and hereditary syndromes}

Of the patients without hereditary cancer syndromes, 38 out of the 330 patients $(11.5 \%)$ had other malignancies before or after diagnosis of ACC. Breast and 
Table 1 Patients' characteristics.

\begin{tabular}{lr}
\hline Characteristics & $\boldsymbol{n = 3 3 0}(\%)$ \\
\hline Race & \\
Caucasian & $281(85.2)$ \\
Other & $49(14.8)$ \\
Gender & \\
$\quad$ Female & $212(64.2)$ \\
$\quad$ Male & $118(35.8)$ \\
Hormonally functioning tumors & \\
$\quad$ Yes & $138(41.8)$ \\
$\quad$ No & $192(58.2)$ \\
Anatomic site & \\
Left adrenal & $177(53.8)$ \\
Right adrenal & $153(46.2)$ \\
ENSAT stage & \\
I & $11(3.3)$ \\
II & $123(37.3)$ \\
III & $111(33.6)$ \\
IV & $85(25.8)$ \\
\hline
\end{tabular}

prostate cancers were the most common (seven patients with breast cancer $(18.4 \%)$ and seven patients with prostate cancer $(18.4 \%))$. Other malignancies were skin cancer (four patients, 10.5\%), non-small cell lung cancer (four patients, $10.5 \%$ ), endometrial carcinoma (three patients, 7.9\%), papillary thyroid cancer (two patients, $5.2 \%$ ), renal cell carcinoma (two patients, $5.2 \%$ ), melanoma (two patients, 5.2\%), bladder cancer (one patient, $2.6 \%$ ), colorectal carcinoma (one patient, $2.6 \%$ ), cervical cancer (one patient, 2.6\%), ovarian carcinoma (one patient, $2.6 \%$ ), acute lymphoblastic leukemia (one patient, 2.6\%), and malignant tumors of undetermined etiology (two patients, 5.2\%).

Six patients had Li-Fraumeni syndrome (diagnosed clinically or through genetic testing), one had multiple endocrine neoplasia type 1 , and another patient had a familial history of ACC. No patients had Beckwith-Wiedemann syndrome or familial adenomatous polyposis.

Table 2 Comparison of patient characteristics and outcomes in this study with those reported previously from our institution.

\begin{tabular}{|c|c|c|c|}
\hline & $\begin{array}{l}\text { Before } 1980 \\
\text { (5) } n=78(\%)\end{array}$ & $\begin{array}{c}1980-1997(5) \\
n=139(\%)\end{array}$ & $\begin{array}{c}1998-2011^{\mathrm{a}} \\
n=330\end{array}$ \\
\hline Mean age (years) & 41.7 & 45.8 & 46.8 \\
\hline \multicolumn{4}{|l|}{ Gender } \\
\hline Male & $34(44)$ & 55 (39) & $118(36)$ \\
\hline Female & $44(56)$ & $84(61)$ & $212(64)$ \\
\hline \multicolumn{4}{|l|}{ Extent of disease } \\
\hline Local & $21(27)$ & $46(33)$ & $134(40)$ \\
\hline Regional & $23(29)$ & 46 (33) & $111(34)$ \\
\hline Distant & $34(44)$ & $47(34)$ & $85(26)$ \\
\hline $\begin{array}{l}\text { Functioning } \\
\text { tumor }\end{array}$ & $26(33)$ & 47 (34) & $138(42)$ \\
\hline \multicolumn{4}{|l|}{ Survival rate (\%) } \\
\hline 2 years & NA & 61 & 64 \\
\hline 5 years & NA & 47 & 38 \\
\hline
\end{tabular}

${ }^{\text {aThis report. }}$

\section{Treatment utilization}

Resection of the primary tumor was performed in 275 $(83.3 \%)$ patients $(n=45(16.4 \%)$ at MD Anderson and $n=230(83.6 \%)$ outside MD Anderson). Open resection was performed in $244(88.7 \%)$ patients and laparoscopic in $31(11.2 \%)$ patients. Negative resection margins (R0) were achieved in 153 patients $(55.6 \%)$. Positive margins (R1) were found in 47 patients $(17.1 \%)$ and (R2) resection margins were found in 28 patients $(10.2 \%)$. Margin status was unknown (RX) in 47 patients $(17.1 \%)$.

Mitotane was used in $235(71.2 \%)$ of the 330 patients either as monotherapy or in combination with other systemic chemotherapy. Of these, 67 $(28.5 \%)$ achieved serum mitotane level of $14 \mathrm{mg} / \mathrm{l}$ or higher. The median OS for those patients with levels of $14 \mathrm{mg} / \mathrm{l}$ and higher was 4.1 years (95\% CI: $2.8,7.0$ years) compared with 2.9 years (95\% CI: 2.2, 3.8 years) for those who had lower mitotane levels. At 5-years after diagnosis, overall survival was $44 \%$ (95\% CI: $32-60 \%$ ) in patients with mitotane levels $14 \mathrm{mg} / \mathrm{l}$ or higher compared with $45 \%$ (95\% CI: $27-44 \%)$ in those with lower mitotane levels. Figure 1 illustrates overall survival curves in both groups.

Radiation therapy was used in 58 patients $(18 \%)$ mostly as a palliative measure in metastatic disease, while adjuvant radiation therapy after primary resection was used only in 16 patients (5\%) (29). More than 20 different traditional chemotherapy regimens were administered as first line systemic therapy and data were available for 163 patients (Table 3).

\section{Recurrence and survival}

In patients who had surgical resection $(n=275)$, the median local-recurrence-free time was 1.0 year $(95 \% \mathrm{CI}$ : 0.9-1.4). In univariate analysis, factors associated with local recurrence were surgical resection outside MD Anderson $(P=0.035)$, positive surgical margins $(P=0.007)$, and advanced disease stage $(P=0.026)$ as shown in Table 4. On multivariate analysis, the hazard ratios for local recurrence $(95 \% \mathrm{CI})$ including site of surgery (MDACC vs outside MDACC), stage ( $1 / 2$ vs $3 / 4$ ), and margin (negative vs positive) were 0.603 (0.402-0.902), $0.749(0.533-1.053)$, and 0.746 (0.541-1.030) respectively. Other factors were not

Table 3 First-line chemotherapy regimens for patients with adrenocortical carcinoma.

\begin{tabular}{lcccc}
\hline & $\begin{array}{c}\text { Etoposide/ } \\
\text { ctoposide/ } \\
n=46 \\
(28.2 \%)\end{array}$ & $\begin{array}{c}n=58 \\
\text { doxorubicin/ } \\
\text { cisplatin } \\
(35.6 \%)\end{array}$ & $\begin{array}{c}\text { Other } \\
\text { regimens } \\
n=59 \\
(36.1 \%)\end{array}$ & $\begin{array}{c}\text { No. of } \\
\text { patients } \\
n=163\end{array}$ \\
\hline Neoadjuvant & 6 & 10 & 8 & 24 \\
For metastasis & 40 & 48 & 51 & 139 \\
\hline
\end{tabular}


Table 4 Local-recurrence-free time of patients with adrenocortical carcinoma.

\begin{tabular}{lcclc}
\hline & \multicolumn{3}{c}{ Local-recurrence-free $(95 \% \mathrm{Cl})$} & \multirow{P}{*}{$\boldsymbol{P}$ value } \\
\cline { 2 - 4 } Characteristic & Median years & Rate at 3 years & Rate at 5 years & \\
\hline $\begin{array}{l}\text { Surgery } \\
\text { At MD Anderson }\end{array}$ & $1.56(0.82-5.52)$ & $0.36(0.24-0.55)$ & $0.32(0.2-0.52)$ & 0.03 \\
$\quad$ Not at MD Anderson & $1.01(0.83-1.37)$ & $0.26(0.21-0.33)$ & $0.12(0.08-0.18)$ & \\
Margin status & $1.29(1-1.79)$ & $0.29(0.23-0.38)$ & $0.15(0.1-0.23)$ & 0.007 \\
$\quad$ R0 & $0.72(0.42-1.03)$ & $0.18(0.1-0.3)$ & $0.12(0.06-0.24)$ & \\
R1/R2 & $1.37(1.04-2.06)$ & $0.33(0.25-0.42)$ & $0.18(0.12-0.26)$ & 0.02 \\
$\begin{array}{l}\text { Disease stage } \\
\text { I/II }\end{array}$ & $0.84(0.69-1.21)$ & $0.24(0.17-0.33)$ & $0.13(0.08-0.21)$ & \\
III/IV & & & & \\
\hline
\end{tabular}

associated with local recurrence and included gender, hormonal overproduction, and tumor location (right vs left).

Distant metastases were documented in 218 (66\%) of the 330 patients during follow-up, with the lungs $(66 \%)$, liver $(57 \%)$, and bone $(17 \%)$ being the most common sites.

The median overall survival time for all patients $(n=330)$ was 3.2 years (95\% CI: $2.7-4.0$ years). The median follow-up time for censored observations was 2.7 years (range: 0.1-25.1 years). The median overall survival times in relation to disease stage were as follows: stage I $(n=11,3.3 \%), 24.1$ years $(95 \% \mathrm{CI}$ : 3.2 - not reached); stage II $(n=123,37.2 \%), 6.1$ years (95\% CI: 4.9-7.2); stage III $(n=111,33.6 \%)$, 3.5 years (95\% CI: $2.6-6.2)$; stage IV $(n=85,25.7 \%)$, 0.9 years (95\% CI: $0.7-1.1)$. In univariable analysis, factors associated with poor survival were functioning tumors, R1/R2 surgical resections, stage III or IV at diagnosis, and venous thromboembolism (Fig. 2). Other factors such as gender and resection of five or more lymph nodes at time of initial surgery were not associated with overall survival. Older age, functioning tumors, and high disease stage at diagnosis remained significant prognostic factors associated with poor survival in a multivariable Cox proportional hazards model (Table 5).

\section{Discussion}

The current study investigates a large number of patients with ACC treated at a single institution. Compared with previous reports from our institution obtained during different time periods, patients in the current study tended to be diagnosed at an older age, have more localized tumors, and more functioning tumors. Our cohort's 5-year survival rate of $38 \%$ is similar to those reported by others $(6,30,31,32)$, although we noticed a slightly lower 5 -year survival rate than those reported from the same institution in the past. As we did not review the source documents from the older series, direct comparisons could not be done to assess if these differences are truly statistically significant. In addition, the variability in methodology may explain some of the differences in retrospectively collected data. The variation is likely small for certain outcomes (such as age, gender, date of diagnosis, death, and treatments received) but may be significant for other variables (such as performance status and certain operative complications) $(33,34,35)$. In this large cohort, patients were older than patients reported in previous reports from our institution and had a higher percentage of localized disease and functioning tumors at the time of diagnosis. It remains unclear if these differences are due to increased detection of tumors at an earlier stage or a change in referral pattern. The presence of functioning tumors could lead to distinct clinical manifestations associated with excessive hormonal production and prompts further imaging studies. The theoretical benefit of earlier detection of functioning tumors is likely negated by the increased morbidityassociated hormonally active tumors compared with nonfunctioning tumors.

Surgery remains the treatment of choice for ACC ( 32 , $36,37)$, as it is the only therapeutic approach that can be curative for localized disease. In our study, complete resections of primary tumors were associated with both

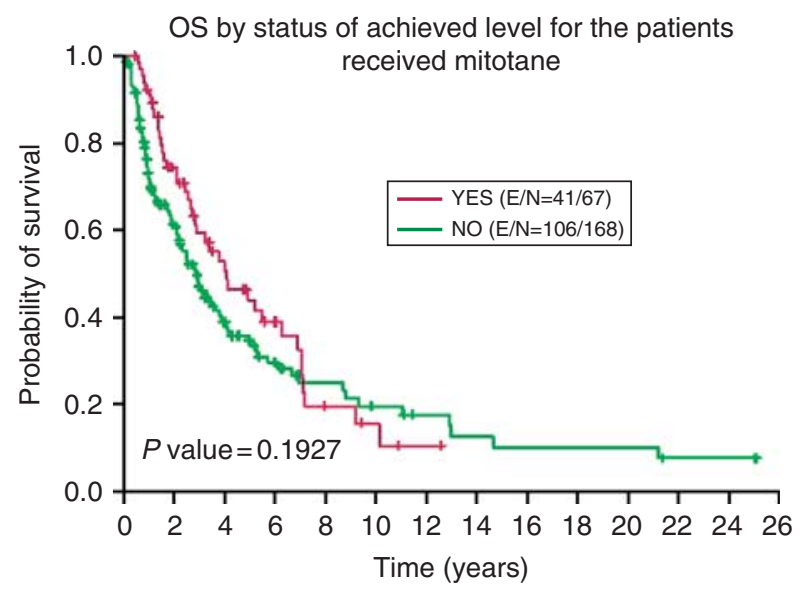

Figure 1 Overall survival (OS) in patients who achieved mitotane levels of $14 \mathrm{mg} / \mathrm{l}$ or higher (YES, red line) compared with the patients with lower levels (NO, green line). 
Table 5 Multivariable Cox proportional hazards model for overal survival of patients with adrenocortical carcinoma.

\begin{tabular}{lcc}
\hline Prognostic factor & $\boldsymbol{P}$ value & $\begin{array}{c}\text { Hazard ratio } \\
(95 \% \mathrm{Cl})\end{array}$ \\
\hline $\begin{array}{l}\text { Age at diagnosis } \\
\text { Functioning tumors vs } \\
\text { nonfunctioning tumors }\end{array}$ & 0.0089 & $1.013(1.003-1.024)$ \\
Stage I/II vs III/IV & 0.0196 & $1.400(1.055-1.857)$ \\
\hline
\end{tabular}

decreased disease recurrence and better overall survival (36), which are in agreement with findings reported in previous studies $(7,26,31)$. Median time to recurrence was about 1 year. Factors associated with local recurrence, other than incomplete resection, were resection performed outside of MD Anderson and advanced disease stage at diagnosis. In addition, we have recently described higher recurrence rates (especially peritoneal carcinomatosis) with laparoscopic resection when compared with open resection (38). The improved survival in patients operated on at MD Anderson is in line of literature from Europe that suggested improved outcome in ACC patients who received their care in referral centers known for their expertise in ACC (39). Adequate pre-operative imaging is crucial to plan initial surgical treatment as well as subsequent adjuvant therapy and should include imaging of the chest, abdomen, and pelvis. In the past few years, there has been an increasing use of markers of cell proliferation (such as Ki67\%) as prognostic markers to help with treatment decisions especially after primary tumor resection $(40,41,42)$. In our study, almost $83 \%$ of the patients had their initial surgery outside our institution and this referral pattern resulted in lack of consistency in reporting proliferation markers (including Ki67\%) and Weiss score. The absence of this information is a shortcoming of our study and similar

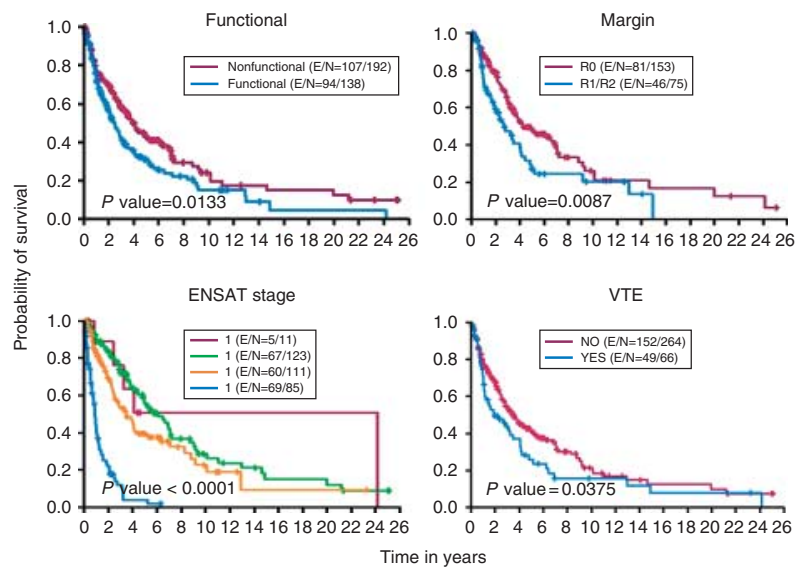

Figure 2 Factors associated with the overall survival of patients with adrenocortical carcinoma. R0, no evidence of tumor; R1, microscopically positive resection margins; $\mathrm{R} 2$, macroscopic residual disease; ENSAT, European Network for the Study of Adrenal Tumors; VTE, venous thromboembolism. large cohort studies published in the past decade $(5,7$, $8,22)$. This limitation reinforces the need to have a standardized pathological template that would contain key pathological features (e.g., Weiss score, Ki67\%, resection margins) to facilitate a uniform interpretation and generalization of pathological data in ACC.

Figure 3 illustrates our current algorithm in approaching patients with localized ACC that combines the use of molecular markers (Ki67\%) with other information such as resection margin and ENSAT stage for risk stratification and choosing adjuvant therapy.

The most common sites of distant metastasis in our study were the lungs and liver, followed by bone, in agreement with previous reports $(43,44,45)$. Although it would have been useful to include the extent of the disease in the survival analysis, the imaging studies utilized (CT, MRI, PET scan and bone scan) at the time of diagnosis varied between patients during the study period. The lack of uniformity in the imaging studies may lead to a difference in the number of metastases identified and therefore could estimate inaccurately the burden of disease at diagnosis.

For patients with metastatic disease or unresectable tumors, the options are limited. Mitotane has been approved for ACC as an adjuvant therapy and for the treatment of advanced disease $(46,47)$. Moreover, the first randomized prospective study (ADIUVO trial, http://clinicaltrials.gov/ct2/show/study/NCT00777 244) to assess efficacy of adjuvant mitotane in low-risk patients who underwent surgical resection is open for patient recruitment. In our study, mitotane was used in $71 \%$ of the patients, where almost $29 \%$ achieved therapeutic levels. We observed that the survival curves of the patients who achieved a mitotane level of $14 \mathrm{mg} / \mathrm{l}$ or higher showed early separation when compared with the patients with lower levels of mitotane. We believe this separation corresponds to the periods when most

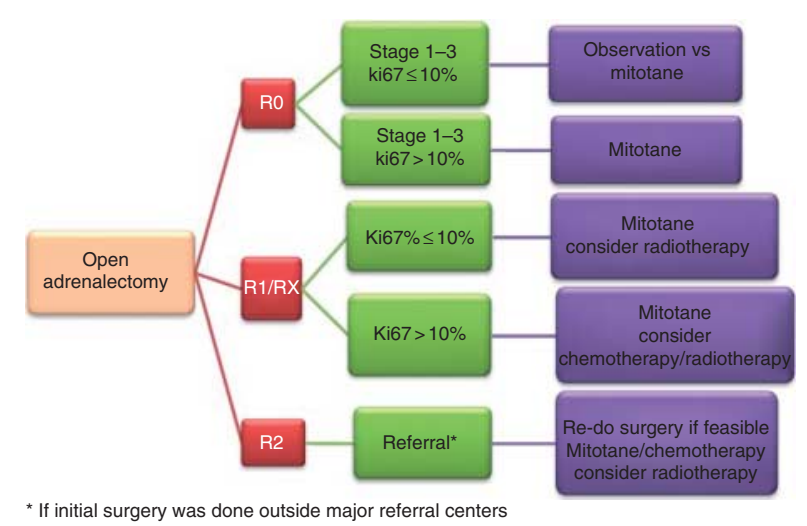

Figure $3 \mathrm{~A}$ suggested algorithm for the management of localized adrenocortical carcinoma. R0, no evidence of tumor; R1, microscopic evidence of tumor; R2, macroscopic residual disease; $\mathrm{RX}$, margins unknown. We recommend mitotane for 2-3 years. 


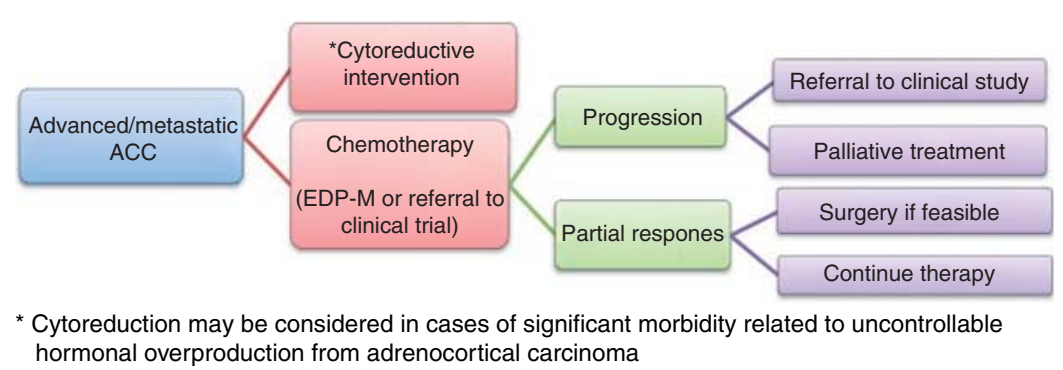

Figure 4 An algorithm for the management of locally advanced/metastatic adrenocortical carcinoma. patients would have been receiving mitotane and suggests a beneficial effect of reaching a therapeutic level of $14-20 \mathrm{mg} / \mathrm{l}$, as shown repeatedly in the literature. Unfortunately, the retrospective nature of this review limited our ability to capture the mitotane dose, side-effect profile, or exact times of therapy.

Currently used systemic therapies often combine mitotane with systemic agents. In the only completed phase III trial of ACC, the combination of etoposide, doxorubicin, and cisplatin with mitotane was superior to the combination of streptozocin with mitotane in terms of progression-free survival (5 vs 2.1 months); however, the two groups did not differ significantly in overall survival (24). In our cohort, cisplatin/etoposide and etoposide/ doxorubicin/cisplatin regimens were the most common. In a previous study from our group, neither regimen conferred a significant advantage (48). Therefore, there is an urgent need for more efficacious treatment for this lethal disease. In fact, we have recently published our experience of dual inhibition of the IGF1 receptor and mTOR pathway, where stable disease was achieved for more than 6 months in $42 \%$ of the patients (49). Figure 4 illustrates our current management plan for patients with advanced/metastatic ACC.

The use of adjuvant radiotherapy in the context of ACC remains unclear. While some authors have proposed a decrease in local recurrences after adjuvant radiotherapy $(48,50)$, in a recent study published by our group that included the 16 patients who received adjuvant radiotherapy, we were unable to demonstrate improved survival, recurrence rate, or time to recurrence (29). Further prospective, multicenter studies are needed to better determine the impact of radiotherapy on recurrence and survival.

ACC in children is extremely rare, with an estimated incidence of 19 new cases per year in the United States (51). Carriers of TP53 mutations and some genetic syndromes are conditions that have been associated with ACC in children. In fact, it is estimated that about $50-80 \%$ of children with ACC carry a germline TP53 mutation $(52,53)$, making Li-Fraumeni syndrome the most common inherited condition in young patients with ACC. In our cohort, 12 patients $(3.6 \%)$ were younger than 18 years old at the age of diagnosis, and $50 \%$ of the pediatric patients (six of 12) had Li-Fraumeni syndrome based upon clinical grounds or genetic testing.

Similar to older reports $(25,54)$, approximately one out of ten patients with nonhereditary ACC patients had other malignancies, with breast and prostate cancer being the most frequent ones. Despite this apparent risk for other malignancies, we only recommend ageappropriate cancer screening that is adjusted per personal and family history in the few patients who have long-term survival.

This study was limited by the inherent shortcomings of retrospective reviews and potential referral bias. Referral bias is likely more pronounced in rare diseases that require special expertise compared with more common illnesses that require well set standards of care and commonly available treatments (55). The main factors to cause this bias include the tendency to refer patients if they have unusual presentation, after failing prior treatments, and/or if they have advanced disease that requires special expertise. In ACC, referral bias is expected to result in worse outcome for the whole group if most inclusion subjects were referred after failing prior treatments.

Also, it is unknown how many patients are treated outside major centers and never referred for inclusion in such study design. Some of these patients may have been cured and did not require further treatment or they may have accepted their diagnosis as being terminal and chose to stay in their local communities (56). In our series, most of the patients had their initial surgical resection outside MDACC and then referred and it was often difficult to ascertain the cause of referral in all cases or the temporal relationship between recurrence and referral.

Nevertheless, the current study has multiple strengths including the summary of clinical experience with a large cohort of ACC patients treated at a single institution over the past decade, and description of our treatment approach in this rare disease.

The unchanged mortality observed over the decades in our cohort, which has also been described by a recent population study done in The Netherlands (8), underscores the urgency to find better treatments for ACC. 


\section{Conclusions}

Despite better understanding of molecular pathways involved in ACC and the availability of new classes of anti-cancer therapy, the prognosis of ACC remains poor. Older age at diagnosis, functioning tumors, and incomplete resections are clinical factors associated with worse survival. Surgical expertise is important to achieve complete resections and to improve outcome. There is an urgent need for more efficacious systemic treatments than those currently used, as distant recurrence and ultimate death are very common despite the best efforts at locoregional control of disease.

\section{Declaration of interest}

The authors declare that there is no conflict of interest that could be perceived as prejudicing the impartiality of the research reported.

\section{Funding}

This paper is supported in part by the National Institutes of Health through The University of Texas MD Anderson Cancer Center Support Grant, CA016672, and The Beverlin Fund for Adrenal Cancer Research.

\section{References}

1 Gerhardt PR, Handy VH \& Ferber B. Trends in cancer incidence, mortality, and probability in the state of New York. New York State Journal of Medicine 195757 1387-1390.

2 Griswold $\mathrm{MH} \&$ Cutler SJ. The Connecticut cancer register. Seventeen years of experience, 1956. Connecticut Medicine 2006 70 323-328.

3 Soreide JA, Brabrand K \& Thoresen SO. Adrenal cortical carcinoma in Norway, 1970-1984. World Journal of Surgery 199216 663-667 (discussion 668). (doi:10.1007/BF02067349)

4 Nader S, Hickey RC, Sellin RV \& Samaan NA. Adrenal cortical carcinoma. A study of 77 cases. Cancer $1983 \mathbf{5 2}$ 707-711. (doi:10.1002/1097-0142(19830815)52:4<707::AID-CNCR28 20520424>3.0.CO;2-N)

5 Vassilopoulou-Sellin R \& Schultz PN. Adrenocortical carcinoma. Clinical outcome at the end of the 20th century. Cancer 200192 1113-1121. (doi:10.1002/1097-0142(20010901)92:5<1113 ::AID-CNCR1428>3.0.CO;2-I)

6 Abiven G, Coste J, Groussin L, Anract P, Tissier F, Legmann P, Dousset B, Bertagna X \& Bertherat J. Clinical and biological features in the prognosis of adrenocortical cancer: poor outcome of cortisol-secreting tumors in a series of 202 consecutive patients. Journal of Clinical Endocrinology and Metabolism $2006 \mathbf{9 1}$ 2650-2655. (doi:10.1210/jc.2005-2730)

7 Icard P, Goudet P, Charpenay C, Andreassian B, Carnaille B, Chapuis Y, Cougard P, Henry JF \& Proye C. Adrenocortical carcinomas: surgical trends and results of a 253-patient series from the French Association of Endocrine Surgeons study group. World Journal of Surgery 200125 891-897. (doi:10.1007/ s00268-001-0047-y)

8 Kerkhofs TM, Verhoeven RH, Van der Zwan JM, Dieleman J, Kerstens MN, Links TP, Van de Poll-Franse LV \& Haak HR. Adrenocortical carcinoma: a population-based study on incidence and survival in the Netherlands since 1993. European Journal of Cancer 20132 S0959-8049(13)00173-1

9 Ramsay O. Malignant tumors of the suprarrenal glands. Bulletin of the Johns Hopkins Hospital 1899 94-96 20-29.
10 Hench PS, Kendall EC, Slocumb CH \& Polley HF. The effects of the adrenal cortical hormone 17-hydroxy-11-dehydrocorticosterone (compound E) on the acute phase of rheumatic fever; preliminary report. Proceedings of the Staff Meetings. Mayo Clinic $1949 \mathbf{2 4}$ 277-297.

11 Hutter AM Jr \& Kayhoe DE. Adrenal cortical carcinoma. Results of treatment with o,p'DDD in 138 patients. American Journal of Medicine $1966 \mathbf{4 1}$ 581-592. (doi:10.1016/0002-9343(66) 90220-8)

12 Varley JM, McGown G, Thorncroft M, Cochrane S, Morrison P, Woll P, Kelsey AM, Mitchell EL, Boyle J, Birch JM et al. A previously undescribed mutation within the tetramerisation domain of TP53 in a family with Li-Fraumeni syndrome. Oncogene 199612 2437-2442.

13 Groden J, Thliveris A, Samowitz W, Carlson M, Gelbert L, Albertsen H, Joslyn G, Stevens J, Spirio L, Robertson M et al. Identification and characterization of the familial adenomatous polyposis coli gene. Cell 199166 589-600. (doi:10.1016/00928674(81)90021-0)

14 Tissier F, Cavard C, Groussin L, Perlemoine K, Fumey G, Hagnere AM, Rene-Corail F, Jullian E, Gicquel C, Bertagna X et al. Mutations of $\beta$-catenin in adrenocortical tumors: activation of the Wnt signaling pathway is a frequent event in both benign and malignant adrenocortical tumors. Cancer Research 200565 $7622-7627$.

15 Hatada I, Ohashi H, Fukushima Y, Kaneko Y, Inoue M, Komoto Y, Okada A, Ohishi S, Nabetani A, Morisaki H et al. An imprinted gene p57KIP2 is mutated in Beckwith-Wiedemann syndrome. Nature Genetics 199614 171-173. (doi:10.1038/ng1096-171)

16 Gicquel C, Raffin-Sanson ML, Gaston V, Bertagna X, Plouin PF, Schlumberger M, Louvel A, Luton JP \& Le Bouc Y. Structural and functional abnormalities at $11 \mathrm{p} 15$ are associated with the malignant phenotype in sporadic adrenocortical tumors: study on a series of 82 tumors. Journal of Clinical Endocrinology and Metabolism 1997 82 2559-2565. (doi:10.1210/jc.82.8.2559)

17 Weksberg R, Shen DR, Fei YL, Song QL \& Squire J. Disruption of insulin-like growth factor 2 imprinting in Beckwith-Wiedemann syndrome. Nature Genetics $1993 \mathbf{5}$ 143-150. (doi:10.1038/ ng1093-143)

18 Heaton JH, Wood MA, Kim AC, Lima LO, Barlaskar FM, Almeida MQ, Fragoso MC, Kuick R, Lerario AM, Simon DP et al. Progression to adrenocortical tumorigenesis in mice and humans through insulin-like growth factor 2 and $\beta$-catenin. American Journal of Pathology $2012 \mathbf{1 8 1}$ 1017-1033. (doi:10.1016/ j.ajpath.2012.05.026)

19 Soon PS, Gill AJ, Benn DE, Clarkson A, Robinson BG, McDonald KL \& Sidhu SB. Microarray gene expression and immunohistochemistry analyses of adrenocortical tumors identify IGF2 and Ki- 67 as useful in differentiating carcinomas from adenomas. EndocrineRelated Cancer 200916 573-583. (doi:10.1677/ERC-08-0237)

20 Ozata DM, Caramuta S, Velazquez-Fernandez D, Akcakaya P, Xie H, Hoog A, Zedenius J, Backdahl M, Larsson C \& Lui WO. The role of microRNA deregulation in the pathogenesis of adrenocortical carcinoma. Endocrine-Related Cancer 201118 643-655. (doi:10.1530/ERC-11-0082)

21 DeLellis RA LR, Heitz PU \& Eng C. Pathology and genetics of tumours of endocrine organs. In World Health Organization Classification of Tumours. IARC Press, 2004.

22 Fassnacht M, Johanssen S, Quinkler M, Bucsky P, Willenberg HS, Beuschlein F, Terzolo M, Mueller HH, Hahner S, Allolio B et al. Limited prognostic value of the 2004 International Union Against Cancer staging classification for adrenocortical carcinoma: proposal for a Revised TNM Classification. Cancer 2009115 243-250. (doi:10.1002/cncr.24030)

23 Lughezzani G, Sun M, Perrotte P, Jeldres C, Alasker A, Isbarn H, Budaus L, Shariat SF, Guazzoni G, Montorsi F et al. The European Network for the Study of Adrenal Tumors staging system is prognostically superior to the international union against cancer-staging system: a North American validation. European Journal of Cancer 201046 713-719. (doi:10.1016/ j.ejca.2009.12.007) 
24 Fassnacht M, Terzolo M, Allolio B, Baudin E, Haak H, Berruti A, Welin S, Schade-Brittinger C, Lacroix A, Jarzab B et al. Combination chemotherapy in advanced adrenocortical carcinoma. New England Journal of Medicine 2012366 2189-2197. (doi:10.1056/NEJMoa1200966)

25 Venkatesh S, Hickey RC, Sellin RV, Fernandez JF \& Samaan NA. Adrenal cortical carcinoma. Cancer 1989 64 $765-769$. (doi:10.1002/1097-0142(19890801)64:3 < 765::AID-CNCR28 20640333>3.0.CO;2-I)

26 Pommier RF \& Brennan MF. An eleven-year experience with adrenocortical carcinoma. Surgery 1992112 963-970 (discussion 970-961).

27 Schulick RD \& Brennan MF. Long-term survival after complete resection and repeat resection in patients with adrenocortical carcinoma. Annals of Surgical Oncology 19996 719-726. (doi:10.1007/s10434-999-0719-7)

28 Lee JE, Berger DH, el-Naggar AK, Hickey RC, VassilopoulouSellin R, Gagel RF, Burgess MA \& Evans DB. Surgical management, DNA content, and patient survival in adrenal cortical carcinoma. Surgery 1995118 1090-1098. (doi:10.1016/S0039-6060 (05)80119-9)

29 Habra MA, Ejaz S, Feng L, Das P, Deniz F, Grubbs EG, Phan A, Waguespack SG, Ayala-Ramirez M, Jimenez C et al. A retrospective cohort analysis of the efficacy of adjuvant radiotherapy after primary surgical resection in patients with adrenocortical carcinoma. Journal of Clinical Endocrinology and Metabolism 2013 98 192-197. (doi:10.1210/jc.2012-2367)

30 Bilimoria KY, Shen WT, Elaraj D, Bentrem DJ, Winchester DJ, Kebebew E \& Sturgeon C. Adrenocortical carcinoma in the United States: treatment utilization and prognostic factors. Cancer 2008 113 3130-3136. (doi:10.1002/cncr.23886)

31 Paton BL, Novitsky YW, Zerey M, Harrell AG, Norton HJ, Asbun H, Kercher KW \& Heniford BT. Outcomes of adrenal cortical carcinoma in the United States. Surgery 2006140 914-920 (discussion 919-920). (doi:10.1016/j.surg.2006.07.035)

32 Kendrick ML, Lloyd R, Erickson L, Farley DR, Grant CS, Thompson GB, Rowland C, Young WF Jr \& van Heerden JA. Adrenocortical carcinoma: surgical progress or status quo? Archives of Surgery 2001136 543-549. (doi:10.1001/archsurg. 136.5.543)

33 Shiloach M, Frencher SK Jr, Steeger JE, Rowell KS, Bartzokis K, Tomeh MG, Richards KE, Ko CY \& Hall BL. Toward robust information: data quality and inter-rater reliability in the American College of Surgeons National Surgical Quality Improvement Program. Journal of the American College of Surgeons 2010 210 6-16. (doi:10.1016/j.jamcollsurg.2009.09.031)

34 Hutter MM, Rowell KS, Devaney LA, Sokal SM, Warshaw AL, Abbott WM \& Hodin RA. Identification of surgical complications and deaths: an assessment of the traditional surgical morbidity and mortality conference compared with the American College of Surgeons-National Surgical Quality Improvement Program. Journal of the American College of Surgeons 2006203 618-624. (doi:10.1016/j.jamcollsurg.2006.07.010)

35 Beard CM, Yunginger JW, Reed CE, O'Connell EJ \& Silverstein MD. Interobserver variability in medical record review: an epidemiological study of asthma. Journal of Clinical Epidemiology $1992 \mathbf{4 5}$ 1013-1020. (doi:10.1016/0895-4356(92)90117-6)

36 Grubbs EG, Callender GG, Xing Y, Perrier ND, Evans DB, Phan AT \& Lee JE. Recurrence of adrenal cortical carcinoma following resection: surgery alone can achieve results equal to surgery plus mitotane. Annals of Surgical Oncology $2010 \quad 17 \quad 263-270$. (doi:10.1245/s10434-009-0716-x)

37 Schteingart DE, Doherty GM, Gauger PG, Giordano TJ, Hammer GD, Korobkin M \& Worden FP. Management of patients with adrenal cancer: recommendations of an international consensus conference. Endocrine-Related Cancer 200512 667-680. (doi:10.1677/ erc.1.01029)

38 Cooper AB, Habra MA, Grubbs EG, Bednarski BK, Ying AK, Perrier ND, Lee JE \& Aloia TA. Does laparoscopic adrenalectomy jeopardize oncologic outcomes for patients with adrenocortical carcinoma? Surgical Endoscopy $2013 \quad \mathbf{2 7} 4026-4032$. (doi:10.1007/s00464-013-3034-0)

39 Hermsen IG, Kerkhofs TM, den Butter G, Kievit J, van Eijck CH, Nieveen van Dijkum EJ, Haak HR \& Dutch Adrenal N. Surgery in adrenocortical carcinoma: importance of national cooperation and centralized surgery. Surgery 2012152 50-56. (doi:10.1016/ j.surg.2012.02.005)

40 Terzolo M, Boccuzzi A, Bovio S, Cappia S, De Giuli P, Ali A, Paccotti P, Porpiglia F, Fontana D \& Angeli A. Immunohistochemical assessment of Ki-67 in the differential diagnosis of adrenocortical tumors. Urology 200157 176-182. (doi:10.1016/ S0090-4295(00)00852-9)

41 Stojadinovic A, Ghossein RA, Hoos A, Nissan A, Marshall D, Dudas M, Cordon-Cardo C, Jaques DP \& Brennan MF. Adrenocortical carcinoma: clinical, morphologic, and molecular characterization. Journal of Clinical Oncology 200220 941-950. (doi:10.1200/JCO.20.4.941)

42 Morimoto R, Satoh F, Murakami O, Suzuki T, Abe T, Tanemoto M, Abe M, Uruno A, Ishidoya S, Arai Y et al. Immunohistochemistry of a proliferation marker Ki67/MIB1 in adrenocortical carcinomas: Ki67/MIB1 labeling index is a predictor for recurrence of adrenocortical carcinomas. Endocrine Journal 200855 49-55. (doi:10.1507/endocrj.K07-079)

43 Datrice NM, Langan RC, Ripley RT, Kemp CD, Steinberg SM, Wood BJ, Libutti SK, Fojo T, Schrump DS \& Avital I. Operative management for recurrent and metastatic adrenocortical carcinoma. Journal of Surgical Oncology 2012105 709-713. (doi:10.1002/jso.23015)

44 Erdogan I, Deutschbein T, Jurowich C, Kroiss M, Ronchi C, Quinkler M, Waldmann J, Willenberg HS, Beuschlein F, Fottner C et al. The role of surgery in the management of recurrent adrenocortical carcinoma. Journal of Clinical Endocrinology and Metabolism 201398 181-191. (doi:10.1210/jc.2012-2559)

45 Bellantone R, Ferrante A, Boscherini M, Lombardi CP, Crucitti P, Crucitti F, Favia G, Borrelli D, Boffi L, Capussotti L et al. Role of reoperation in recurrence of adrenal cortical carcinoma: results from 188 cases collected in the Italian National Registry for Adrenal Cortical Carcinoma. Surgery 1997122 1212-1218. (doi:10.1016/S0039-6060(97)90229-4)

46 Haak HR, Hermans J, van de Velde CJ, Lentjes EG, Goslings BM, Fleuren GJ \& Krans HM. Optimal treatment of adrenocortical carcinoma with mitotane: results in a consecutive series of 96 patients. British Journal of Cancer 199469 947-951. (doi:10.1038/bjc.1994.183)

47 Terzolo M, Angeli A, Fassnacht M, Daffara F, Tauchmanova L, Conton PA, Rossetto R, Buci L, Sperone P, Grossrubatscher E et al. Adjuvant mitotane treatment for adrenocortical carcinoma. New England Journal of Medicine 2007356 2372-2380. (doi:10.1056/ NEJMoa063360)

48 Fareau GG, Lopez A, Stava C \& Vassilopoulou-Sellin R. Systemic chemotherapy for adrenocortical carcinoma: comparative responses to conventional first-line therapies. Anticancer Drugs 200819 637-644. (doi:10.1097/CAD.0b013e328300542a)

49 Naing A, Lorusso P, Fu S, Hong D, Chen HX, Doyle LA, Phan AT, Habra MA \& Kurzrock R. Insulin growth factor receptor (IGF-1R) antibody cixutumumab combined with the mTOR inhibitor temsirolimus in patients with metastatic adrenocortical carcinoma. British Journal of Cancer 2013108 826-830. (doi:10.1038/bjc.2013.46)

50 Polat B, Fassnacht M, Pfreundner L, Guckenberger M, Bratengeier K, Johanssen S, Kenn W, Hahner S, Allolio B \& Flentje M. Radiotherapy in adrenocortical carcinoma. Cancer 2009115 2816-2823. (doi:10.1002/cncr.24331)

51 Lack EE, Mulvihill JJ, Travis WD \& Kozakewich HP. Adrenal cortical neoplasms in the pediatric and adolescent age group. Clinicopathologic study of 30 cases with emphasis on epidemiological and prognostic factors. Pathology Annual 199227 1-53.

52 Varley JM, McGown G, Thorncroft M, James LA, Margison GP, Forster G, Evans DG, Harris M, Kelsey AM \& Birch JM. Are there 
low-penetrance TP53 Alleles? evidence from childhood adrenocortical tumors American Journal of Human Genetics 199965 995-1006. (doi:10.1086/302575)

53 Varley JM. Germline TP53 mutations and Li-Fraumeni syndrome. Human Mutation 2003 21 313-320. (doi:10.1002/humu.10185)

54 Didolkar MS, Bescher RA, Elias EG \& Moore RH. Natural history of adrenal cortical carcinoma: a clinicopathologic study of 42 patients. Cancer $1981 \mathbf{4 7}$ 2153-2161. (doi:10.1002/ 1097-0142(19810501)47:9 < 2153::AID-CNCR2820470908> 3.0.CO;2-6)

55 Layde PM, Broste SK, Desbiens N, Follen M, Lynn J, Reding D \& Vidaillet H. Generalizability of clinical studies conducted at tertiary care medical centers: a population-based analysis. Journal of Clinical Epidemiology $1996 \quad \mathbf{4 9} \quad 835-841 . \quad$ (doi:10.1016/ 0895-4356(96)00006-6)

56 Sutherland LR \& Verhoef MJ. Patients who seek a second opinion: are they different from the typical referral? Journal of Clinical Gastroenterology 198911 308-313. (doi:10.1097/ 00004836-198906000-00013)

Received 24 June 2013

Revised version received 30 August 2013

Accepted 1 October 2013 